\title{
A CONTINUUM MODEL FOR HOUSING ALLOCATION AND TRANSPORTATION EMISSION PROBLEMS IN A POLYCENTRIC CITY
}

\author{
Jun YIN \\ Department of Civil Engineering, The University of Hong Kong, Pokfulam Road, \\ Hong Kong SAR, China \\ E-mail: yinjun@hku.hk; Tel: +852-2859-2662; Fax: +852-2517-0124

\section{S. C. WONG} \\ Department of Civil Engineering, The University of Hong Kong, Pokfulam Road, \\ Hong Kong SAR, China \\ E-mail: hhecwsc@hkucc.hku.hk; Tel: +852-2859-1964; Fax: +852-2559-5337
}

N. N. SZE

Department of Civil Engineering, The University of Hong Kong, Pokfulam Road, Hong Kong SAR, China

E-mail: nnsze@graduate.hku.hk; Tel: +852-2859-2662; Fax: +852-2517-0124

\section{H.W. HO}

Department of Civil and Structural Engineering, The Hong Kong Polytechnic University, Hung Hom, Kowloon, Hong Kong SAR, China

E-mail: cehwho@polyu.edu.hk; Tel: +852-2766-4480; Fax:+852-2334-6389

\begin{abstract}
The effect of vehicle emissions on the global climate has prompted increasing concern in the past few decades. Housing development patterns determine people's travel behavior and related vehicle emissions. In this study, we consider a hypothetical city with several central business districts (CBDs) serving several classes of road users, which are continuously distributed over the city. The road network is relatively dense and can be approximated as a continuum. We establish a bi-level model to describe the relationships among housing allocation, traffic volume, and $\mathrm{CO}_{2}$ emissions with a continuum modeling approach. At the lower level, the model achieves the user equilibrium condition of a transport system. At the upper level, it optimizes housing allocation to achieve minimum $\mathrm{CO}_{2}$ emissions. The finite element method, Newton-Raphson algorithm, and convex combination approach are applied to solve the constrained optimization problem established in the bi-level model. A numerical example is then given to illustrate the effectiveness and efficiency of the proposed bi-level approach and solution algorithm in modeling transport demand, traffic intensity, and $\mathrm{CO}_{2}$ emissions with an optimized housing development pattern.
\end{abstract}

Keywords: Continuum modeling, transport emission, housing allocation pattern, bi-level programming, finite element method.

\section{INTRODUCTION}

Because of its negative effects on ecosystems, economies, and health, global warming has become one of the most acute problems of our time. Human activities, mainly those involving 
the combustion of fossil fuels, have caused an increase in greenhouse gases (GHGs), particularly $\mathrm{CO}_{2}$, which has resulted in a rise in global temperatures. It is reported that the transport sector was responsible for about a quarter of global $\mathrm{CO}_{2}$ emissions in 2003, and this proportion is even higher in developed countries (ECMT, 2007). About three quarters of transport-related $\mathrm{CO}_{2}$ emissions are generated by road surface transport (IEA, 2006).

Applying advanced technologies in the design of vehicles to increase the level of fuel efficiency is one way of reducing traffic-related emissions. However, regulating the emission rate alone may not be effective in reducing overall emissions, because the number of cars on the road and length of driving periods may increase rapidly. Transport policies such as changing land use, managing transport demand, and improving transit systems can have a significant effect on the behavior of travelers, and thereby on transport-related emissions (Nagurney and Ramanujam, 1998; Nagurney, 2000a; Nagurney, 2000b; Poudenx, 2008; Harwatt et al., 2011). In our study, we focus on such emissions.

Many studies have attempted to analyze the effect of travel patterns and transportation system design on transport emissions. Congestion charges, the topology of transport networks, traffic control methods, the road environment, signal intersections, and the design and maintenance of road networks are all essential influencing factors (Rakha et al., 2000; Nagurney, 2000a; Nagurney, 2000b; Yin and Lawphongpanich, 2006; Chiou and Chen, 2010; Nagurney et al., 2010; Chen et al., 2011; Li et al., in press). An analytical framework has been established to decompose the transportation emissions problem into the dimensions of population, transport intensity, energy intensity, and carbon intensity. This approach allows the aggregate effect of traveler activities, vehicle design, and fuel technologies on transport emissions to be estimated for different transport subsectors (Yang et al., 2009). Land-use patterns influence residential density, mixed land use, car ownership levels, commuting distance, and household travel demand and associated emissions (Cervero, 1989; Nowlan and Stewart, 1991; Messenger and Ewing, 1996; Cervero, 1996a; Cervero and Radisch, 1996b; McNally and Kulkarni, 1997; Badoe and Miller, 2000; Boarnet and Crane, 2001; Bento et al., 2003; Bhat and Guo, 2007; Brownstone and Golob, 2009); thus, they have diverse and significant effects on traffic-related emissions (Norman et al., 2006). Once a land use pattern is established, it is difficult to change, so the initial planning phase is highly important for minimizing transportrelated emissions.

To better understand the relationship between land use and travel demand, more research is needed (Boarnet and Sarmiento, 1998). Previous studies have been implemented in a discrete manner, focusing on a specific road network, which requires a detailed understanding of the study's objectives. Such an approach also makes it difficult to determine the interactions among urban form, land use, transport policies, transport systems, and transport-related emissions/energy consumption. Integrated models offer an alternative for improving our understanding of these issues and allow us to consider aggregate effects. A case study was carried out in Seattle to determine such interactions (Frank et al., 2000). It offered an effective model that integrated land use, transportation, and vehicle emission patterns, and reduced the complexity of the problem through the use of indirect discrete models.

In this study, we apply the continuum modeling approach (Sasaki et al., 1990; Wong, 1998; Wong et al., 1998) to study the interactions among land use, transport, and emissions. In contrast to the discrete modeling approach, it focuses on the general trends and patterns of distribution and the travel choices of road users at the macroscopic rather than microscopic level. There are many benefits to using a continuum modeling approach, especially in the 
initial planning stage. We use some smooth mathematical equations to describe the travel behavior of road users, which makes the problem more manageable (compared with the actual number of links required for discrete modeling) and can reveal how the characteristics of the road network are influenced by several parameters, such as the perceptions of road users. In addition, the continuum model does not require such intensive data collection, which is often labor intensive and sometimes infeasible, especially in the initial phase of planning. Ho and Wong established a continuum model to reveal the relationships among transport demand, urban form, and travel behavior, which satisfies the user equilibrium principle (Ho and Wong, 2005), and then extended it to a bi-level model with housing allocation optimized to obtain the minimal negative utility, which included housing and transportation costs (Ho and Wong, 2007). Based on earlier studies (Wong and Yang, 1999; Yang and Wong, 2000; Ho et al., 2006; Ho et al., in press), we extend the existing bi-level continuum transportation modeling approach to incorporate the multi-CBD problem and try to minimize transportrelated emissions in the upper level. We first review some typical emission modeling approaches in Section 2. In Section 3, we describe the formulation of the proposed bi-level continuum model, with user equilibrium achieved in the lower level and housing allocation optimized in the upper one. The finite element method (FEM) and convex optimization method are applied in this section. In Section 4, we present a numerical example to demonstrate the effectiveness and efficiency of the proposed model given a multi-class commuter scenario. Finally, concluding remarks are given in Section 5.

\section{EMISSION MODELING APPROACHES}

The models currently used to estimate transport emissions can be classified into three categories. In the first category are emission factor models, which consist of two parts, the baseline emission rate and correction factors. Both are derived from the mean value of repeated measurements following a standard method, such as the Federal Test Procedure (FTP). Correction factors incorporate the influence of factors such as vehicle speed, temperature, fuel type, and vehicle age. The emission rate is obtained by multiplying the baseline emission rate and correction factors together. The widely used MOBILE and EMFAC models fall into this category (EPA, 1994; CARB, 2006). These models can be used to estimate the emissions of large-scale areas. However, they do not take into consideration either the vehicle operation state or the driving environment. The second category includes the physical power-demand models, which provide a more accurate way of estimating the second-by-second emissions for different driving conditions and vehicle types as they consider both the vehicle's operational conditions and the driving environment. A research group at the University of California, Riverside, established the comprehensive modal emission model (CMEM) (Barth et al., 1996; An et al., 1997; Scora and Barth, 2006), which defines the vehicle emission rate as a function of vehicle operation characteristics, such as engine power, engine speed, air/fuel ratio, fuel use, engine-out emissions, and catalyst pass fraction, for each of six vehicle operation moduli. However, the difficulty of obtaining detailed information on operational characteristics at different vehicle speeds and acceleration, and for different vehicle types, hinders its application. The third category consists of the acceleration and speed-based models, in which the emission rate is defined as a function of the vehicle type, instantaneous speed, and acceleration. Earlier versions of these models derived the average emission rate based on estimates of fourteen typical driving moduli (Joumard et al., 1995). Then, based on the data obtained from the ORNL (Oak Ridge National Laboratory), the emission rate is denoted as a function of a combination of linear, quadratic, and cubic transforms of both the instantaneous speed and acceleration (Ahn et al., 
1999; Ahn et al., 2002; Rakha et al., 2004). This microscopic model can also be extended to a mesoscopic model to estimate the influence of signal intersections and the number of stops during driving (Rakha et al., 2000; Dion et al., 2000). This modeling approach is promising, as less detailed engine operation and driving environment information is required, compared with the physical power-demand models, and the influence of vehicle movement is controlled, which it is not in the emission factor models.

We apply the acceleration and speed-based modeling approach to estimate the transport emission rate with a bi-level continuum transportation model given optimized housing allocation, user equilibrium, and minimized $\mathrm{CO}_{2}$ emissions. This model provides a bridge between travel behavior and traffic-related emissions. The use of this emission modeling approach in a continuum transportation system is appealing. By applying the continuum modeling approach, we can describe the interactions among the road network, urban form, travel behavior, and transport-related emissions in a simple way. The integrated model can then reveal how the global road network characteristics influence transport demand, travel intensity, and traffic-related emissions.

\section{METHODOLOGY}

We formulate the problem as a bi-level program as follows.

\subsection{Lower-level subprogram}

\subsubsection{Model formulation}

In this section, we study a city of arbitrary shape with more than one central business district (CBD), as shown in Figure 1. The road network outside the CBDs is assumed to be relatively dense and can be approximated as a continuum. Transport demand and housing provision are continuously distributed outside the CBDs, and all employment occurs within them. People travel between their homes and the CBDs along the least costly route during peak hours. Their choice of destination is determined by their perception of the travel cost and the externalities of the CBDs. Several classes of road users with different types of travel behavior, perceptions of the travel cost, and housing costs are considered in the housing allocation model, and the number of each class of road users is fixed. We denote the region of the city as $\Omega$, the outer boundary of the city as $\Gamma$, the location of CBD $n$ as $O_{n}$, and the boundary of CBD $n$ as $\Gamma_{c n}$. We assume that road users will not travel across the outer boundary $(\Gamma)$ of the city.

At location $(x, y)$, we define $\mathbf{f}_{m n}(x, y)=\left(f_{x m n}(x, y), f_{y m n}(x, y)\right)$ as the flow vector of class $m$ road users heading to CBD $n$ (expressed as the number of commuters that cross a unit width), where $f_{x m n}(x, y)$ and $f_{y m n}(x, y)$ are the flow flux in the $x$ and $y$ directions, respectively. $\left|\mathbf{f}_{m n}(x, y)\right|=\sqrt{f_{x m n}(x, y)^{2}+f_{y m n}(x, y)^{2}}$ is the corresponding flow intensity. At a particular location $(x, y)$ and for a given flow pattern $\mathbf{f}_{m n}(x, y)$, we define the speed as a monotonic decreasing function of the total flow intensity $v(x, y)=v\left(\sum_{n=1}^{N_{n}} \sum_{m=1}^{N_{m}}\left|\mathbf{f}_{m n}(x, y)\right|\right)$. 
Next, we define the travel cost potential. Let $c(x, y)$ be the local travel cost, which is related to the travel speed as

$$
c(x, y)=1 / v(x, y),
$$

where the travel cost is expressed in hours per unit length of movement at location $(x, y)$. As travel speed is a monotonically decreasing function of the total flow intensity, we define a BPR-type relationship between local travel cost and traffic intensity as follows.

$$
c(x, y)=1 / v(x, y)=c_{0}(x, y)+\eta(x, y)\left(\sum_{n=1}^{N_{n}} \sum_{m=1}^{N_{m}}\left|\mathbf{f}_{m n}(x, y)\right|\right)^{\theta(x, y)}, \forall(x, y) \in \Omega,
$$

where $c_{0}(x, y)$ is the free-flow travel time, and $\eta(x, y)$ and $\theta(x, y)$ are congestion sensitivity parameters at location $(x, y)$. Let $p_{m}$ be the value of time for class $m$ commuters. The travel cost of class $m$ commuters can be expressed in dollars per unit length of travel at $(x, y)$ as

$$
c_{m}(x, y)=p_{m} c(x, y), \forall(x, y) \in \Omega, m \in N_{m} .
$$

For a given flow pattern $\mathbf{f}_{m n}(x, y)$ and with the unit travel cost $c_{m}(x, y)$, we consider the function $u_{m n}(x, y)$, which is the transportation cost of class $m$ commuters at location $(x, y)$ traveling to $\operatorname{CBD} n$, and the following equation should be satisfied:

$$
c_{m}(x, y) \frac{\mathbf{f}_{m n}(x, y)}{\left|\mathbf{f}_{m n}(x, y)\right|}+\nabla u_{m n}(x, y)=0, \forall(x, y) \in \Omega, m \in N_{m}, n \in N_{n} .
$$

Equation (4) is equivalent to equations (5) and (6), which are, respectively:

$$
\begin{gathered}
c_{m}(x, y) \frac{f_{x m n}(x, y)}{\left|\mathbf{f}_{m n}(x, y)\right|}+\frac{\partial u_{m n}(x, y)}{\partial x}=0, \forall(x, y) \in \Omega, m \in N_{m}, n \in N_{n}, \text { and } \\
c_{m}(x, y) \frac{f_{y m n}(x, y)}{\left|\mathbf{f}_{m n}(x, y)\right|}+\frac{\partial u_{m n}(x, y)}{\partial y}=0, \forall(x, y) \in \Omega, m \in N_{m}, n \in N_{n} .
\end{gathered}
$$

In equation (4), the flow vector is the direct opposite of the gradient of the scalar function $u_{m n}(x, y)$; that is,

$$
-\mathbf{f}_{m n}(x, y) / / \nabla u_{m n}(x, y), \forall \mathbf{f}_{m n} \neq 0,(x, y) \in \Omega,
$$

where "//" means that the two vectors are in the same direction.

For each type of commuter, the flow vector and trip demand must satisfy the flow conservation conditions in the region of the city.

$$
\nabla \mathbf{f}_{m n}(x, y)-q_{m n}(x, y)=0, \forall(x, y) \in \Omega, m \in N_{m}, n \in N_{n},
$$

where $\nabla \mathbf{f}_{m n}(x, y)=\partial f_{x m n} / \partial x+\partial f_{y m n} / \partial y$ is the gradient of the flow vector $\mathbf{f}_{m n}(x, y)$, and $q_{m n}(x, y)$ is the density of the demand of class $m$ commuters at location $(x, y)$ that will travel to $\operatorname{CBD} n$, which is expressed as the number of commuters per unit area per unit time.

In addition to the transportation cost are the costs that are incurred in each CBD, which are known as market externalities. An externality is specified as a function of the market share of the facility and represented as $S_{m n}$ (expressed in the same unit as the transportation cost, HKD) for class $m$ commuter perceptions of CBD $n$. It can be decreasing, indicating a positive externality (economies of scale, employment opportunities), increasing, showing a negative externality (congestion), or convex, when the positive externality is small and the negative externality is large. This is because some CBD costs are fixed (such as investment in infrastructure) and should be shared by all road users, so that the larger is the demand, the 
smaller is the cost. However, greater demand causes severe congestion, which results in more delays and additional costs. In our model, $S_{m n}$ can be defined as a function of $V_{n}$ (the total demand for CBD $n$ ), where $V_{n}=\sum_{m=1}^{N_{m}} \iint_{\Omega} q_{m n} d \Omega$, and $V_{n}$ is the sum of all classes of road users that will travel to $\operatorname{CBD} n$. Then, the perceived cost of class $m$ users traveling to $\operatorname{CBD} n$ can be denoted as $C_{m n}$ :

$$
C_{m n}=\theta_{m n}+S_{m n}\left(V_{n}\right),
$$

where $\theta_{m n}$ is the biased component that represents the preference of class $m$ users for CBD $n$.

Then, the total perceived cost for each class of road users traveling to the CBDs can be defined as $\pi_{m n}$ :

$$
\pi_{m n}(x, y)=C_{m n}+u_{m n}(x, y), \forall(x, y) \in \Omega, m \in N_{m}, n \in N_{n} .
$$

For any used route $p$ of class $m$ from the location $(H)$ to CBD $n$, the total perceived cost (including the transportation cost and the CBD's externalities) is

$$
\begin{aligned}
C_{p} & =C_{m n}+\int_{p} C_{m} d s=C_{m n}+\int_{p} C_{m} \frac{\mathbf{f}_{m n}}{\left|\mathbf{f}_{m n}\right|} \mathbf{d} \mathbf{s}=C_{m n}-\int_{p} \nabla u_{m n} \mathbf{d s}=C_{m n}-\left(u_{m n}\left(O_{n}\right)-u_{m n}(H)\right) \\
& =C_{m n}+u_{m n}(H)
\end{aligned}
$$

For any unused route $\bar{p}$ of class $m$ from the location $(H)$ to CBD $n$, the total perceived cost (including the transportation cost and the CBD's externalities) is

$$
\begin{aligned}
C_{\bar{p}} & =C_{m n}+\int_{\bar{p}} c_{m} d s \geq C_{m n}+\int_{\bar{p}} C_{m} \frac{\mathbf{f}_{m n}}{\left|\mathbf{f}_{m n}\right|} \mathbf{d s}=C_{m n}-\int_{\bar{p}} \nabla u_{m n} \mathbf{d s}=C_{m n}-\left(u_{m n}\left(O_{n}\right)-u_{m n}(H)\right) \\
& =C_{m n}+u_{m n}(H)=C_{p}
\end{aligned}
$$

The inequality in equation (12) is due to the fact that for route $\bar{p}$, the vectors $\mathbf{f}_{m n} /\left|\mathbf{f}_{m n}\right|$ and ds are not parallel, and thus $d s \geq\left(\mathbf{f}_{m n} /\left|\mathbf{f}_{m n}\right|\right) \cdot \mathbf{d s}$. Hence, for the unused route, the total perceived cost is at least no less than that of the used routes. The model thus guarantees that users will choose the least costly route between their home and destination in a user-optimal manner.

For a particular class of users, the probability of a user choosing a CBD as his destination depends on the total perceived cost from his home to his destination, which is governed by a logit-type distribution:

$$
q_{m n}(x, y)=q_{m}(x, y) \frac{\exp \left(-\chi_{m} \pi_{m n}(x, y)\right)}{\sum_{i=1}^{N_{n}} \exp \left(-\chi_{m} \pi_{m i}(x, y)\right)}, \forall(x, y) \in \Omega, m \in N_{m}, n \in N_{n},
$$

where $\chi_{m}$ is a positive scalar parameter that measures the sensitivity.

Next, we define $\Pi_{m}(x, y)$ as a function of the log-sum cost of the users from the location $(x, y)$ to all of the CBDs.

$$
\Pi_{m}(x, y)=-\frac{1}{\chi_{m}} \ln \sum_{i=1}^{N_{n}} \exp \left(-\chi_{m} \pi_{m i}(x, y)\right), \forall(x, y) \in \Omega, m \in N_{m} .
$$

The interaction between housing allocation and traffic equilibrium is governed by the demand distribution function, which is used to describe the way in which road users choose their 
home location in the city. Ho and Wong (2005, 2007) identified housing and travel costs as the basic variables that affect a commuter's choice of where to live; in this case, we also take the externalities of the CBDs into consideration. The following equation is used to incorporate the housing allocation problem into the transportation equilibrium problem.

$$
q_{m}(x, y)-Q_{m} \frac{\exp \left(-\gamma_{m} U_{m}(x, y)\right)}{\iint_{\Omega} \exp \left(-\gamma_{m} U_{m}(x, y)\right) d \Omega}=0, \forall(x, y) \in \Omega, m \in N_{m},
$$

where $Q_{m}$ is the total demand of class $m$ commuters, which is fixed in this model, $U_{m}$ is the utility function perceived by class $m$ commuters for all CBDs at the location $(x, y)$, and $\gamma_{m}$ is a positive scalar parameter that measures the sensitivity.

The utility function $U_{m}(x, y)=\Pi_{m}(x, y)+\bar{r}_{m}(x, y)$ consists of two components. The log-sum cost is obtained in equation (14) and the housing cost, which depends on the total demand density $q(x, y)=\sum_{m=1}^{N_{m}} q_{m}(x, y)$ and the total housing supply density $H(x, y)$, in the following equation.

$$
\bar{r}_{m}(x, y)=\alpha_{m}(x, y)(1+\beta(x, y) q(x, y) /(H(x, y)-q(x, y))),
$$

where $\alpha_{m}(x, y)$ represents different commuter perceptions of housing costs, and $\beta(x, y)$ are scalar parameters that represent the demand-dependent components of the housing cost function at location $(x, y)$.

By combining equations (13) and (15), we can find $\forall(x, y) \in \Omega, m \in N_{m}, n \in N_{N}$ :

$$
q_{m n}(x, y)-Q_{m} \frac{\exp \left(-\gamma_{m} U_{m}(x, y)\right)}{\iint_{\Omega} \exp \left(-\gamma_{m} U_{m}(x, y)\right) d \Omega} \times \frac{\exp \left(-\chi_{m} \pi_{m n}(x, y)\right)}{\sum_{i=1}^{N_{n}} \exp \left(-\chi_{m} \pi_{m i}(x, y)\right)}=0 .
$$

We also consider the boundary conditions that must be satisfied:

$$
\begin{gathered}
u_{m n}=0, \forall(x, y) \in \Gamma_{c n}, \forall m \in N_{m}, \forall n \in N_{n}, \text { and } \\
\mathbf{f}_{m n}=0, \forall(x, y) \in \Gamma, \Gamma_{c k}, \forall m \in N_{m}, n, k \in N_{n}, n \neq k .
\end{gathered}
$$

In equation (18), as users at $\Gamma_{c n}$ are already at the boundary of $\operatorname{CBD} n$, they will incur no transportation cost in traveling to CBD $n$. In equation (19), we assume that there is no flow across the city boundary and that class $m$ road users do not enter any CBD other than the one to which they are heading.

\subsubsection{Solution algorithm}

The problem can be written as a system of differential equations, including equations (5), (6), (8), and (17), which is solved using the finite element method (FEM) (Zienkiewicz and Taylor, 1989). We first adopt the Galerkin formulation of the weighted residual technique to transform the equations into the following expressions, where $\Psi(x, y)$ is the weight function in the weighted residual technique and can take any value. For $\forall(x, y) \in \Omega, m \in N_{m}, n \in N_{n}$, the following equations can be obtained.

$$
\iint_{\Omega}\left(c_{m}(x, y) \frac{f_{x m n}(x, y)}{\left|\mathbf{f}_{m n}(x, y)\right|}+\frac{\partial u_{m n}(x, y)}{\partial x}\right) \Psi(x, y) d \Omega=0,
$$




$$
\begin{gathered}
\iint_{\Omega}\left(c_{m}(x, y) \frac{f_{y m n}(x, y)}{\left|\mathbf{f}_{m n}(x, y)\right|}+\frac{\partial u_{m n}(x, y)}{\partial y}\right) \Psi(x, y) d \Omega=0, \\
\iint_{\Omega}\left(\nabla \mathbf{f}_{m n}(x, y)-q_{m n}(x, y)\right) \Psi(x, y) d \Omega=0, \text { and } \\
\iint_{\Omega}\left(q_{m n}(x, y)-Q_{m} \frac{\exp \left(-\gamma_{m} U_{m}(x, y)\right)}{\iint_{\Omega} \exp \left(-\gamma_{m} U_{m}(x, y)\right) d \Omega} \times \frac{\exp \left(-\chi_{m} \pi_{m n}(x, y)\right)}{\sum_{i=1}^{N_{n}} \exp \left(-\chi_{m} \pi_{m i}(x, y)\right)} \Psi(x, y) d \Omega=0 .\right.
\end{gathered}
$$

After the region is discretized, we can set the local interpolation function $N(x, y)$ to $\Psi(x, y)$, because $\Psi(x, y)$ can be any value. For a specific node $s$, the governing equations for all classes of commuters are given as follows.

$$
\mathbf{r}_{s m n}(\boldsymbol{\Psi})=\left\{\begin{array}{c}
\sum_{e \in T_{s}} \iint_{\Omega_{e}}\left(c_{m}(x, y) \frac{f_{x m n}(x, y)}{\left|\mathbf{f}_{m n}(x, y)\right|}+\frac{\partial u_{m n}(x, y)}{\partial x}\right) N_{s}(x, y) d \Omega \\
\sum_{e \in T_{s}} \iint_{\Omega_{e}}\left(c_{m}(x, y) \frac{f_{y m n}(x, y)}{\left|\mathbf{f}_{m n}(x, y)\right|}+\frac{\partial u_{m n}(x, y)}{\partial y}\right) N_{s}(x, y) d \Omega \\
\sum_{e \in T_{s}} \iint_{\Omega_{e}}\left(\nabla \mathbf{f}_{m n}(x, y)-q_{m n}(x, y)\right) N_{s}(x, y) d \Omega \\
\sum_{e \in T_{s}} \iint_{\Omega_{e}}\left(q_{m n}(x, y)-\frac{Q_{m} \exp \left(-\gamma_{m} U_{m}(x, y)\right)}{\iint_{\Omega} \exp \left(-\gamma_{m} U_{m}(x, y)\right) d \Omega} \times \frac{\exp \left(-\chi_{m} \pi_{m n}(x, y)\right)}{\sum_{i=1}^{N_{n}} \exp \left(-\chi_{m} \pi_{m i}(x, y)\right)}\right) N_{s}(x, y) d \Omega
\end{array}\right\}
$$

where $\Omega_{e}$ denotes the region of the elements $e, T_{s}$ is the set of elements that connects with node $s, N_{s}(x, y)$ is the local interpolation function of the element that connects with node $s$, and $\mathbf{r}_{s m n}$ is the nodal residual vector for class $m$ commuters with a preference for CBD $n$ at node $s$. $\mathbf{r}_{\text {smn }}=0$ means that the governing equations (5), (6), (8), and (17) can be satisfied locally.

For the global satisfaction of the governing equations, we require that

$$
\mathbf{R}(\boldsymbol{\Psi})=\operatorname{Col}\left(\mathbf{r}_{\text {smn }}(\boldsymbol{\Psi})\right)=0 \text {. }
$$

Boundary conditions (18) and (19) can be satisfied by forcing the specific variables to take a known value, which is very common in FEM. For this system of nonlinear equations, we can apply the Newton-Raphson algorithm with a line search to find a solution, for which we derive the iterative equation

$$
\boldsymbol{\Psi}_{k+1}=\boldsymbol{\Psi}_{k}-\lambda \mathbf{J}_{k}^{-1} \mathbf{R}_{k},
$$

where $\mathbf{J}_{k}$ is the Jacobian matrix of vector $\mathbf{R}_{k}$ at iteration $k$, and $\lambda$ is the step size, which is obtained by a line search to achieve the minimum $|\mathbf{R}(\boldsymbol{\Psi})|$. We compare the relative error $|\mathbf{R}(\boldsymbol{\Psi})| /|\boldsymbol{\Psi}|$ with the acceptable threshold $\varepsilon$. If $|\mathbf{R}(\boldsymbol{\Psi})| /|\boldsymbol{\Psi}|<\varepsilon$, then it is assumed that the solution to equation (26) is found. The solution procedure is summarized as follows.

\section{Solution Procedure A}

Step A1: Find an initial solution for $\boldsymbol{\Psi}_{0}$. Set $k=0$.

Step A2: Evaluate $\mathbf{R}\left(\Psi_{k}\right)$ and $\mathbf{J}\left(\Psi_{k}\right)$. 
Step A3: If the relative error $\left|\mathbf{R}\left(\Psi_{k}\right)\right| /\left|\Psi_{k}\right|$ is less than the accepted error $\varepsilon$, then stop, and take $\boldsymbol{\Psi}_{k}$ as the solution.

Step A4: Otherwise, apply the line search method (with the smallest interval of $\delta$ ) to determine the step size $\lambda^{*}$ that minimizes the norm of the residual vector $\left|\mathbf{R}\left(\boldsymbol{\Psi}_{k+1}-\lambda \mathbf{J}_{k}^{-1} \mathbf{R}_{k}\right)\right|$. Then, $\boldsymbol{\Psi}_{k+1}=\boldsymbol{\Psi}_{k}-\lambda^{*} \mathbf{J}_{k}^{-1} \mathbf{R}_{k}$.

Step A5: Replace $\boldsymbol{\Psi}_{k}$ with $\boldsymbol{\Psi}_{k+1}$. Set $k=k+1$, and go to Step A2.

\subsection{Upper-level subprogram}

\subsubsection{Model formulation}

In this section, we estimate traffic-related $\mathrm{CO}_{2}$ emissions, and also try to minimize emissions by optimizing the housing allocation. The minimization problem of the upper level is modeled as follows.

subject to

$$
\underset{\mathbf{h}}{\operatorname{Minimize}} z(\mathbf{h})=\sum_{n=1}^{N_{n}} \sum_{m=1}^{N_{m}} \iint_{\Omega} \frac{\left|\mathbf{f}_{m n}^{*}(x, y)\right| E_{m n}^{\mathrm{CO} 2}\left(\mathbf{f}^{*}(x, y), \mathbf{a}_{m n}^{*}(x, y)\right)}{v^{*}(x, y)} \mathrm{d} \Omega,
$$

$$
\begin{gathered}
H_{\max }(x, y)-\left(h_{0}(x, y)+h(x, y)\right) \geq 0, \forall(x, y) \in \Omega, \\
h(x, y) \geq 0, \forall(x, y) \in \Omega, \\
B-\iint_{\Omega} P(x, y) h(x, y) d \Omega \geq 0, \forall(x, y) \in \Omega, \\
\iint_{\Omega} h(x, y)+h_{0}(x, y)-q^{*}(x, y) \mathrm{d} \Omega \geq 0, \forall(x, y) \in \Omega,
\end{gathered}
$$

where $\mathbf{f}^{*}(x, y)=\operatorname{col}\left(\mathbf{f}_{m n}^{*}(x, y)\right), \forall m \in N_{m}, n \in N_{n}$, and $\mathbf{a}_{m n}^{*}(x, y)$ is the acceleration vector for class $m$ road users traveling to CBD $n$ under the user equilibrium conditions. The superscript $\left(^{*}\right)$ denotes variables that are the optimal solution from the lower-level subprogram. $h_{0}(x, y)$ is the existing housing provision, and $h(x, y)$ is the additional housing provision at a particular location $(x, y) . H_{\max }(x, y)$ is the maximum possible housing density at location $(x, y)$, which is constrained by topography, the existing transportation infrastructure, and the planned land-use pattern. $B$ is the budget available for additional housing provision, and $P(x, y)$ is the cost of building a housing unit at location $(x, y)$. In terms of the constraints, equation (28) ensures that the total housing development will not exceed the maximum possible housing density; constraint (29) means that there will not be any demolition of the existing housing supply; constraint (30) states that the total investment in housing provision cannot exceed budget $B$; and constraint (31) guarantees that there is sufficient housing provision.

$E_{m n}^{\mathrm{CO} 2}$ is the $\mathrm{CO}_{2}$ emission rate function for class $m$ users heading to $\mathrm{CBD} n$, which is derived using the acceleration and speed-based model. The emission mode proposed by Ahn et al. (1999) is adopted to estimate the emission rate of each class of user as follows.

$$
E^{k}=\exp \left(\sum_{i=0}^{3} \sum_{j=0}^{3} \omega_{i, j}^{k} v^{i} a^{j}\right),
$$

where $a$ is the acceleration $\left(\mathrm{km} / \mathrm{h}^{2}\right), v$ is the speed $(\mathrm{km} / \mathrm{h}), \omega_{i, j}^{k}$ is the model regression coefficient for speed power $i$ and acceleration power $j$, and $E^{k}$ is the instantaneous fuel 
consumption and emission rate, with the superscript $(k)$ denoting different kinds of emissions, $\mathrm{HC}$ and $\mathrm{CO}(\mathrm{mg} / \mathrm{s})$, and fuel consumption (gal/h). The speed is determined by equation (2) with $v(x, y)=1 / c(x, y)$, and the acceleration can be evaluated from the continuum model as follows.

$$
\begin{gathered}
a_{x m n}(x, y)-v_{x m n}(x, y) \frac{\partial v_{x m n}(x, y)}{\partial x}=0, \forall(x, y) \in \Omega, m \in N_{m}, n \in N_{n}, \text { and } \\
a_{y m n}(x, y)-v_{y m n}(x, y) \frac{\partial v_{y m n}(x, y)}{\partial y}=0, \forall(x, y) \in \Omega, m \in N_{m}, n \in N_{n},
\end{gathered}
$$

where $\mathbf{a}_{m n}(x, y)=\left(a_{x m n}(x, y), a_{y m n}(x, y)\right)$ is the acceleration vector of class $m$ commuters heading to $\operatorname{CBD} n, a_{x m n}$ and $a_{y m n}$ are acceleration in the $x$ and $y$ directions, respectively, $\mathbf{v}_{m n}(x, y)=\left(v_{x m n}(x, y), v_{y m n}(x, y)\right)$ is the velocity vector of class $m$ commuters heading to $\operatorname{CBD} n, v_{x m n}(x, y)=v(x, y) \frac{f_{x m n}(x, y)}{\left|\mathbf{f}_{m n}(x, y)\right|}$ and $v_{y m n}(x, y)=v(x, y) \frac{f_{y m n}(x, y)}{\left|\mathbf{f}_{m n}(x, y)\right|}$ are respectively the velocity in the $x$ and $y$ directions for class $m$ commuters traveling to CBD $n, N_{m}$ is the total number of user classes, and $N_{n}$ is the total number of CBDs. Under the route choice governed by the user optimal conditions, commuters may accelerate or decelerate along their trajectory according to the spatial variation in traffic conditions in the neighboring area. The acceleration in the direction of movement is determined by

$$
a=\left(a_{x} f_{x}+a_{y} f_{y}\right) / \sqrt{f_{x}^{2}+f_{y}^{2}} .
$$

Based on the limited parameters that we have, we cannot use this model directly, as we have only the parameters for $\mathrm{HC}, \mathrm{CO}$, and estimated fuel consumption. However, the $\mathrm{CO}_{2}$ emission function, which is shown in equation (36), can be derived based on the carbon balance between fuel consumption and emissions.

where

$$
E^{\mathrm{CO} 2}=2458.29 F-3.17 E^{\mathrm{HC}}-1.57 E^{\mathrm{CO}},
$$

$$
F=\exp \left(\sum_{i=0}^{3} \sum_{j=0}^{3} \omega_{i, j}^{1} v^{i} a^{j}\right), E^{\mathrm{CO}}=\exp \left(\sum_{i=0}^{3} \sum_{j=0}^{3} \omega_{i, j}^{2} v^{i} a^{j}\right), E^{\mathrm{HC}}=\exp \left(\sum_{i=0}^{3} \sum_{j=0}^{3} \omega_{i, j}^{3} v^{i} a^{j}\right),
$$

in which $F$ is the instantaneous fuel consumption (gal/h), and $E^{\mathrm{HC}}, E^{\mathrm{CO}}$, and $E^{\mathrm{CO} 2}$ are the relative gas emission rates (mg/s). The parameters in the expressions of equation (37) are summarized in Table 1. Also, we should make it clear that in this study, we consider just one type of vehicle and road. However, the model can easily be extended to incorporate different vehicle types and road classes.

\subsubsection{Solution algorithm}

The minimization problem is nonlinear. To reduce the difficulty in solving it, we first use the FEM to transform constraints (30) and (31) into linear ones.

$$
\begin{gathered}
B-\sum_{n=1}^{N_{F N}} h_{n} \sum_{e \in \Omega_{e n}} \iint_{\Omega_{e}}\left(P_{e i} N_{i} N_{n}+P_{e j} N_{j} N_{n}+P_{e k} N_{k} N_{n}\right) d \Omega \geq 0, \\
\frac{1}{3} \sum_{n=1}^{N_{F N}} \Delta_{n} h_{n}+\frac{1}{3} \sum_{n=1}^{N_{F N}} \Delta_{n}\left(h_{n}^{0}-q_{n}^{*}\right) \geq 0,
\end{gathered}
$$


where $N_{F N}$ is the total number of finite element nodes within the generated mesh, $N_{j}$ is the interpolation function of the FEM for node $j, P_{e i}$ is the cost of building a housing unit at node $i$ within element $e, \Delta_{n}$ is the area of the finite elements that connect with node $n, \Omega_{e}$ is the region of element $e, \Omega_{e n}$ is the region that connects with node $n, h_{n}^{0}$ and $h_{n}$ are respectively the existing and additional housing provision at node $n$, and $q_{n}^{*}$ is the total demand at node $n$, obtained from the lower-level subprogram.

Also, the total emissions in equation (27) can be written as $Z(\mathbf{h})=\sum_{k=1}^{N_{n}} \sum_{n=1}^{N_{n}} \sum_{m=1}^{N_{m}} \iint_{\Omega_{e}} \frac{\left|\mathbf{f}_{m n}^{*}(x, y)\right| E_{m n}^{\mathrm{CO} 2}\left(\mathbf{f}^{*}(x, y), \mathbf{a}_{m n}^{*}(x, y)\right)}{v^{*}(x, y)} \mathrm{d} \Omega_{e}$ in the FEM scheme.

Then, constraints (28), (29), (38), and (39) can be written as

$$
\mathbf{A h} \geq \mathbf{C},
$$

where $\mathbf{h}=\left(h_{1}, h_{2}, \cdots, h_{N_{F N}}\right)$ is the vector of the additional housing provision. However, in the process of converting the nonlinear constraints into linear ones, we discretize the modeled city without considering the continuity of the housing provision policy. To maintain the continuity of local housing provision, if we provide $t_{i}$ units of housing at location $\left(x_{i}, y_{i}\right)$, then its adjacent location $\left(x_{j}, y_{j}\right)$ is also developed. Let the housing provision at location $\left(x_{j}, y_{j}\right)$, induced by the development at location $\left(x_{i}, y_{i}\right)$, be $h_{i j}$, which is related to the development intensity at $\left(x_{i}, y_{i}\right)$ by $h_{i j}=g_{i j} t_{i}$ in which $g_{i j}$ is defined as

$$
g_{i j}=\frac{\left(1-d_{i j} / I_{i}\right)^{3}}{\iint_{\Omega_{I_{i}}}\left(1-d_{i j} / I_{i}\right)^{3} d \Omega}=\frac{10}{\pi I_{i}^{2}}\left(1-\frac{d_{i j}}{I_{i}}\right)^{3},
$$

where $d_{i j}$ is the distance between $\left(x_{i}, y_{i}\right)$ and $\left(x_{j}, y_{j}\right), I_{i}$ represents the influencing distance of the development at $\left(x_{i}, y_{i}\right)$, and $\Omega_{I_{i}}$ represents the area of influence, which is a circular region with radius $I_{i}$. Note that $\iint_{\Omega_{I_{i}}} g_{i j} d \Omega=1$.

We first identify a certain number $(K)$ of locations $\left(l_{1}, l_{2}, \cdots, l_{K}\right)$ as potential development areas with housing allocation as $\mathbf{t}=\left(t_{1}, t_{2}, \cdots, t_{K}\right)$. Then,

$$
h_{j}=\sum_{i=1}^{K} h_{i j}=\sum_{i=1}^{K} g_{i j} t_{i},
$$

or alternatively, in matrix form,

$$
\mathbf{h}=\mathbf{G t},
$$

where $\mathbf{G}$ is a $N_{F N} \times K$ matrix, and the $j$ th row and ith column element is $g(i, j)$. Then, the optimization problem can be rewritten as follows.

subject to

$$
\underset{\mathbf{h}}{\operatorname{Minimize}} z(\mathbf{h})=z(\mathbf{G t})
$$

$$
\text { AGt } \geq \text { C }
$$

Next, we apply the convex method to solve this problem as follows. 


$$
\underset{\mathbf{w}}{\operatorname{Minimize}} \nabla z(\mathbf{t}) \cdot \mathbf{w}
$$

subject to

$$
\mathbf{A G w} \geq \mathbf{C},
$$

where $\mathbf{w}=\left(w_{1}, \cdots, w_{K}\right)$ is a feasible solution that falls into the region governed by constraints (47). $\mathbf{G w}-\mathbf{h}$ is the direction of descent for the minimization problem (27). We use a line search method to find a step that will guarantee the largest descent.

However, to solve this problem, we must first find the gradient of the object function $z(\mathbf{h})$ and the sensitivity of the lower-level variables $\left(f_{x m n}^{*}, f_{y m n}^{*}, u_{m n}^{*}, q_{m n}^{*}\right)$ to the upper-level ones (h) . By denoting the lower-level variables as $\boldsymbol{\Psi}_{l}^{*}$ and the upper-level ones as $\boldsymbol{\Psi}_{u}^{*}$, equation (25) can be modified to

$$
\mathbf{R}\left(\boldsymbol{\Psi}_{l}^{*}, \boldsymbol{\Psi}_{u}\right)=0 .
$$

By taking a partial derivative of $\boldsymbol{\Psi}_{u}$ on the left-hand side of equation (48), we have

$$
\nabla_{\boldsymbol{\Psi}_{u}} \boldsymbol{\Psi}_{l}^{*}=-J\left(\boldsymbol{\Psi}_{l}^{*}, \boldsymbol{\Psi}_{u}\right)^{-1} \nabla_{\boldsymbol{\Psi}_{u}} R\left(\boldsymbol{\Psi}_{l}^{*}, \boldsymbol{\Psi}_{u}\right) .
$$

Equation (49) is the matrix of the sensitivity of the optimized lower-level variables $\left(\boldsymbol{\Psi}_{l}^{*}\right)$ to the upper-level ones ( $\left.\boldsymbol{\Psi}_{u}\right)$ (Wong et al., 2006), and can be found for each solution of the lower-level subprogram. The following solution procedure is adopted to solve the problem.

\section{Solution Procedure B}

Step B1: $\quad$ Set $k=1$. Take the initial solution for the upper level to be $\boldsymbol{\Psi}_{u 1}=\mathbf{h}_{1}=0$.

Step B2: With $\boldsymbol{\Psi}_{u k}$, solve the lower-level subprogram, which is based on solution procedure A, to find the solution for the lower-level $\boldsymbol{\Psi}_{l k}$.

Step B3: Using $\boldsymbol{\Psi}_{l k}$, evaluate the sensitivity matrix according to equation (49).

Step B4: Use the sensitivity matrix from the lower level to find auxiliary vector $\mathbf{w}_{k}$.

Step B5: Apply the golden section method (with the smallest search interval of $\delta$ ) to find the step size $\lambda_{k}{ }^{*} \in[0,1]$ that maximizes the objective function $z\left(\mathbf{h}_{k}+\lambda_{k}^{*}\left(\mathbf{G w}_{k}-\mathbf{h}_{k}\right)\right)$ from equation (31). Then, set $\mathbf{d}_{k}=\mathbf{h}_{k}+\lambda_{k}^{*}\left(\mathbf{G} \mathbf{w}_{k}-\mathbf{h}_{k}\right)$.

Step B6: If $z\left(\mathbf{d}_{k}\right)>z\left(\mathbf{h}_{k}\right)$, then set $\mathbf{h}_{k+1}=\mathbf{d}_{k}$ and $k=k+1$, and go to Step B2; otherwise, stop and take $\mathbf{h}_{k}$ as the solution to the upper-level subprogram and $\boldsymbol{\Psi}_{l k}$ as the corresponding solution to the lower-level subprogram.

\section{NUMERICAL EXAMPLE}

We now present a numerical example to illustrate the proposed bi-level model with multiple user classes in a continuum network. The hypothetical city has two CBDs, as shown in Figure 1. The city spans about $35 \mathrm{~km}$ from east to west and $25 \mathrm{~km}$ from north to south. The CBDs are located at coordinates $(14,20)$ and $(31,26)$.

In this example, we consider two classes of road users. The total demand of class 1 road users is 45000 units/h, and that of class 2 road users is 65000 units/h. The sensitivity parameters for 
the housing choice functions in equation (17) are 0.0015 and 0.0020 for class 1 and class 2 users, respectively. The sensitivity parameters in equation (15) are 0.012 and 0.010 for class 1 and class 2, respectively. We assume that all users will travel to one of the two CBDs during the morning peak hour. The cost-flow relationship is specified as

$$
c(x, y)=0.0167+1.0 \times 10^{-6}\left(\sum_{n=1}^{2} \sum_{m=1}^{2}\left|\mathbf{f}_{m n}(x, y)\right|\right)^{1.3} \mathrm{~h} / \mathrm{km} .
$$

The instantaneous speed function is then

$$
v(x, y)=1 / c(x, y)=1 /\left(0.0167+1.0 \times 10^{-6}\left(\sum_{n=1}^{2} \sum_{m=1}^{2}\left|\mathbf{f}_{m n}(x, y)\right|\right)^{1.3}\right) \mathrm{km} / \mathrm{h} .
$$

The value of time $p_{m}$ for class 1 and class 2 commuters is $25 \mathrm{HKD} / \mathrm{h}$ and $75 \mathrm{HKD} / \mathrm{h}$, respectively. The housing cost functions are

Class 1 commuter: $\bar{r}_{1}=20 \times(1+40 q /(H-q)) H K D$, and

Class 2 commuter: $\bar{r}_{2}=1 \times(1+40 q /(H-q))$ HKD.

Class 1 commuters are more sensitive to housing costs than are class 2 commuters, which means that they place a greater value on such costs when making a decision about where to live. In contrast, class 2 commuters value the time cost of transportation more, and are thus more sensitive to time.

The perceived CBD cost function consists of biased and demand-related components. The biased coefficients are set as $\theta_{11}=70 \mathrm{HKD}, \theta_{12}=65 \mathrm{HKD}, \theta_{21}=250 \mathrm{HKD}$, and $\theta_{22}=170$ HKD. The market externalities of the CBDs are defined as

Class 1 road users travel to CBD 1: $S_{11}(x, y)=5.0 \times 10^{-9}\left(V_{1}-25000\right)^{2} \mathrm{HKD}$,

Class 1 road users travel to CBD 2: $S_{12}(x, y)=2.5 \times 10^{-9}\left(V_{2}-20000\right)^{2} \mathrm{HKD}$,

Class 2 road users travel to CBD 1: $S_{21}(x, y)=15.0 \times 10^{-9}\left(V_{1}-25000\right)^{2} \mathrm{HKD}$, and

Class 2 road users travel to CBD 2: $S_{22}(x, y)=7.5 \times 10^{-9}\left(V_{2}-20000\right)^{2} \mathrm{HKD}$.

We assume that the existing housing unit $h_{0 n}$ is taken as a constant of 250 units per $\mathrm{km}^{2}$ over the whole city. The maximum possible housing development is assumed to be 600 units per $\mathrm{km}^{2}$, for all locations $(x, y)$. The budget available for additional housing units is assumed to be 1 billon HKD, and the unit provision cost function is

$$
P(x, y)=10000\left(1.4+\frac{0.010}{\sqrt{(x-14)^{2}+(y-20)^{2}}}+\frac{0.005}{\sqrt{(x-31)^{2}+(y-26)^{2}}}\right) \text { HKD/unit. }
$$

This value varies with the distance to the CBDs, as it is assumed that the cost of land acquisition is a function of this distance.

For housing development, we assume that the influencing distance is $5 \mathrm{~km}$ all over the region, and thus $g_{i j}=\frac{2}{5 \pi}\left(1-d_{i j} / 5\right)^{3}$. To ensure simplicity, we assume the potential housing development areas to be the same nodes on the generated mesh.

We first consider the existing situation, in which the lower-level subprogram is used to obtain the travel choice and emission pattern. Then, we assume an uninformed scenario, in which the authority simply uses the budget to allocate additional housing uniformly over the entire city (increasing the housing provision by about 120 units $/ \mathrm{km}^{2}$ ). In this case, only the lower- 
level subprogram is solved. Next, we consider the optimal housing allocation, in which the bi-level optimization is fully utilized. By taking the acceptable error $\varepsilon=10^{-5}$ for the lowerlevel model and the smallest search interval $\delta=0.02$ for the golden section method in both the lower-level and the upper-level model, this numerical example can be solved in five iterations. The convergence curve for the housing provision model is shown in Figure 2.

Table 2 shows the attractions to the two CBDs and the total emission rate under three different scenarios. For class 1 road users, there does not seem to be much difference between CBD 1 and CBD 2, in contrast to class 2 road users. Apart from the locations of the two CBDs, there are several explanations for this. First, for class 1 road users, the biased components of the CBD externalities, which serve as major factors in influencing road user decisions, are almost the same, but for class 2 road users, these components are much lower for CBD 2 than for CBD 1. Second, CBD 2 is less sensitive to the volume of demand, so congestion in CBD 2 will have less influence on the travel pattern than will congestion occurring in CBD 1. After the additional housing units are allocated, the attractions to the two CBDs do not vary much. Regarding $\mathrm{CO}_{2}$ emissions, if we allocate the housing units uniformly over the entire city, ignoring the user behavior characteristics, then total emissions may even be slightly worse, which reveals a "paradox" in that the system becomes worse with additional development and inappropriate resource expenditure. Next, we review the results for the optimal housing allocation.

Figure 3 shows the optimal distribution of housing units when total $\mathrm{CO}_{2}$ emissions from the transportation sector are minimized. Understandably, almost all of the additional housing units are allocated around the two CBDs. The factors that most influence transportation emissions are speed and acceleration. $\mathrm{CO}_{2}$ emissions increase as acceleration changes from negative to positive, and both a higher and a lower speed result in more emissions than does a moderate speed. However, in our model, all road users must choose one of the two CBDs as their destination with no other choices, so the flow intensity in the areas adjacent to the CBDs is determined by the attraction to each $\mathrm{CBD}$, which will not change much during the optimization process. If most of the housing units are located around the CBDs, then the speed around the CBDs will not change much but road users will generally travel shorter distances, thus producing fewer emissions. So, in this numerical example, the additional housing units are concentrated around the CBDs. The key issue for reducing $\mathrm{CO}_{2}$ emissions in this model is to reduce the commuting distance by allocating more housing units around the CBDs. We can also consider another extreme condition: if the biased components of one CBD (for example, CBD 2) are much larger than those of another (CBD 1), then almost everyone will travel to the latter (CBD 1). In this case, CBD 2 acts like an obstacle, such as a hill or a lake, and all of the additional housing units will be allocated in the west of the city, close to CBD 1. This scenario is similar to one that we implemented in a previous study, in which the city had only one CBD.

Figure 2 shows that the reduction in $\mathrm{CO}_{2}$ emissions is not significant. There are several factors that can influence the extent to which the level of these emissions can be reduced, such as the maximum housing density, the budget for housing development, and people's sensitivity to housing costs. As discussed earlier, the reduction in $\mathrm{CO}_{2}$ emissions is achieved by shortening the commuting distance: if the maximum possible housing development increases, then the areas adjacent to the CBDs can accommodate more people, thus resulting in a greater reduction in commuting distance and $\mathrm{CO}_{2}$ emissions. As the budget for housing development and people's sensitivity to housing costs are deterministic, sensitivity analysis is conducted to illustrate their influence on emission levels (see Figure 8). In this numerical 
example, the budget is used up; however, this does not mean that investing more in housing development will necessarily result in a greater reduction in $\mathrm{CO}_{2}$ emissions, and sometimes, even if $\mathrm{CO}_{2}$ emissions are reduced, the investment is not rewarded. First, increasing housing development only in the areas adjacent to the CBDs (where this is possible) can reduce the commuting distance, but if these areas are already developed, more investment will not help, and this constraint will not be bounded in the upper-level optimization problem. Second, for a certain budget, the closer is the development to the CBDs, the greater is the reward, so the reduction in $\mathrm{CO}_{2}$ emissions will become less sensitive to the budget as it increases. As shown in Figure 8a, when the housing allocation is optimized, the total emissions will decrease with the budget for housing development. The sensitivity decreases as the budget increases, such that budget increases beyond 1.02 billion make no difference. At the same time, if road users are more sensitive to housing costs, then the provision of additional housing will change the travel pattern to a greater extent, thus resulting in a larger reduction in traffic-related $\mathrm{CO}_{2}$ emissions. For those who are not influenced by housing costs, such provision will have no effect. As shown in Figure 8b, total emissions change only slightly when people's sensitivity to housing costs increases. In contrast, when total emissions are optimized, they decrease as people's sensitivity to housing costs increases. The results are relevant to decision making about housing development.

Figure 4 shows the transportation costs for different road users with the optimal housing distribution. We can see that, as road users live further from their destinations, they pay greater travel costs; also, in the areas close to the CBDs, the transportation cost becomes more sensitive to the commuting distance because of the relatively lower speed. Figures $4 \mathrm{a}$ and $4 \mathrm{c}$ indicate that if road users heading to CBD 1 live to the east of CBD 2, then the pattern of change in the transportation cost is slightly different and the transportation cost contours are not particularly smooth. CBD 2 acts like an obstacle, because road users cannot travel across CBD 2 directly. To travel to CBD 1, these people first need to travel around CBD 2, where the congestion is severe, and thus their travel costs increase. The actual situation regarding people's travel behavior and routine choices might be very sophisticated, but we do not cover the microscopic mechanisms of how obstacles influence traffic flow in this study. The same situation occurs in Figures $4 \mathrm{~b}$ and $4 \mathrm{~d}$.

Figure 5 shows the demand of different classes of road users for different CBDs. Commuter choices are determined by the perceived cost of transportation, CBD externalities, and housing costs. We can see that class 1 road users consider housing costs to be more important than do class 2 road users, so the pattern of demand of the former differs more between the two housing development patterns. The decisions of class 2 road users are largely determined by the transportation cost and market externalities of the two CBDs, so their choices change only a little. By comparing the eight figures, we can also see that the reduction in $\mathrm{CO}_{2}$ emissions is mostly related to class 1 road users, which coincides with the earlier discussion: the more sensitive people are to housing costs, the greater is the reduction that can be achieved. Demand forecasts can give the government guidance regarding infrastructure development.

Figure 6 shows the distribution of emission rates for class 1 road users heading to CBD 1. For other types of road users, the emission rates are very similar but not the same. This is because, although the speed is the same, the flow trajectories are different, which affects the tangential acceleration in the emission rate estimation. Figure 7 shows the distribution of total emissions across the city, which is obtained by multiplying the flow intensities by the respective emission rates for all users. A higher concentration of emissions occurs around the CBDs due 
to more severe congestion, and because more people decide to travel to CBD 2, the emissions there are higher. The emission rate will in turn affect people's residential choice, which will be studied in the future.

\section{CONCLUSION}

In this study, the continuum modeling approach is extended to solve a bi-level problem to optimize housing allocation to achieve minimum transport-related emissions in an integrated land use and transportation modeling framework. At the lower level, the interaction between housing provision and travel behavior is described, with user equilibrium achieved. At the upper level, total $\mathrm{CO}_{2}$ emissions are estimated, and the optimal housing allocation pattern that minimizes traffic-related emissions is found. The FEM is applied to solve the system of differential equations and transform the nonlinear constraints into linear ones. Finally, a numerical example is given to show the effectiveness and efficiency of the solution algorithms.

There are several possible extensions of the current modeling approach. We could, for instance, consider the housing provision problem with multiple housing types, and different classes of road users with different levels of car ownership. So far, we have studied the emission problem using a static continuum model, in which we can consider only the emission rate at peak hours. A dynamic continuum model will be established to incorporate multiple vehicle classes and time-varying transport demand emission levels into a land-use transportation modeling framework.

\section{ACKNOWLEDGEMENTS}

The work described in this paper was jointly supported by a Research Postgraduate Studentship, an Outstanding Researcher Award, and the Engineering Postdoctoral Fellowship Programme of the University of Hong Kong, and a grant from the Research Grants Council of the Hong Kong Special Administrative Region of China (Project No. HKU7183/08E).

\section{REFERENCES}

AHN, K., RAKHA, H., TRANI, A. \& VAN AERDE, M. 2002. Estimating vehicle fuel consumption and emissions based on instantaneous speed and acceleration levels. ASCE Journal of Transportation Engineering, 128, 182-190.

AHN, K., TRANI, A. A., RAKHA, H. \& VAN AERDE, M. 1999. Microscopic fuel consumption and emission models. Transportation Research Board 78th Annual Meeting. Washington, D. C.

AN, F., BARTH, M., NORBECK, J. \& ROSS, M. 1997. Development of comprehensive modal emissions model operating under hot-stabilized conditions. Transportation Research Record, 1587, 52-62.

BADOE, D. A. \& MILLER, E. J. 2000. Transportation-land-use interaction: Empirical findings in North America, and their implications for modeling. Transportation Research Part D, 5, 235-263.

BARTH, M., AN, F., NORBECK, J. \& ROSS, M. 1996. Modal emissions modeling: A physical approach. Transportation Research Record, 1520, 81-88. 
BENTO, A. M., CROPPER, M. L., MOBARAK, A. M. \& VINHA, K. 2003. The impact of urban spatial structure on travel demand in the United States. The World Bank Development Research Group Infrastructure and Environment.

BHAT, C. R. \& GUO, J. Y. 2007. A comprehensive analysis of built environment characteristics on household residential choice and auto ownership levels. Transportation Research Part B, 41, 506-526.

BOARNET, M. \& CRANE, R. 2001. The influence of land use on travel behavior: Specification and estimation strategies. Transportation Research Part A, 35, 823-845.

BOARNET, M. G. \& SARMIENTO, S. 1998. Can land-use policy really affect travel behaviour? A study of the link between non-work travel and land-use characteristics. Urban Studies, 35, 1155-1169.

BROWNSTONE, D. \& GOLOB, T. F. 2009. The impact of residential density on vehicle usage and energy consumption. Journal of Urban Economics, 65, 91-98.

CARB. 2006. EMFAC 2007 V. 2.3: User's Guide. California Air Resources Board.

CERVERO, R. 1989. America's Suburban Centers: The Land-use-Transportation Link. Boston: Unwin Hyman Inc.

CERVERO, R. 1996a. Mixed land-uses and commuting: Evidence from the American Housing Survey. Transportation Research Part A, 30, 361-377.

CERVERO, R. \& RADISCH, C. 1996b. Travel choices in pedestrian versus automobile oriented neighborhoods. Transport Policy, 3, 127-141.

CHEN, A., ZHOU, Z. \& RYU S. 2011. Modeling physical and environmental side constraints in traffic equilibrium problem. International Journal of Sustainable Transportation, 5, 172-197.

CHIOU, Y.-C. \& CHEN, T.-C. 2010. Direct and indirect factors affecting emissions of cars and motorcycles in Taiwan. Transportmetrica, 6, 215-233.

DION, F., VAN AERDE, M. \& RAKHA, H. 2000. Mesoscopic fuel consumption and vehicle emission rate estimation as a function of average speed and number of stops. Transportation Research Board 79th Annual Meeting. Washington, D. C.

ECMT. 2007. Cutting Transport $\mathrm{CO}_{2}$ Emissions: What Progress? [Online]. European Conference of Ministers of Transport, Paris. Available at: http://www.internationaltransportforum.org/Topics/pdf/07CO2summary.pdf [Accessed April 12 2010].

EPA. 1994. User's Guide to Mobile 5. U.S. Environmental Protection Agency.

FRANK, L. D., STONE, B. \& BACHMAN, W. 2000. Linking land use with household vehicle emissions in the Central Puget Sound: Methodological framework and findings. Transportation Research Part D, 5, 173-196.

HARWATT, H., TIGHT, M. \& TIMMS P. 2011. Personal transport emissions within London: exploring policy scenarios and carbon reductions up to 2050. International Journal of Sustainable Transportation, 5, 270-288.

HO, H. W. \& WONG, S. C. 2005. Combined model of housing location and traffic equilibrium problems in a continuous transportation system. The 16th International Symposium on Transportation and Traffic Theory (ISTTT16). Maryland, U. S. A.

HO, H. W. \& WONG, S. C. 2007. Housing allocation problem in a continuum transportation system. Transportmetrica, 3, 21-39.

HO, H. W., WONG, S. C. \& LOO, B. P. Y. 2006. Combined distribution and assignment model for a continuum traffic equilibrium problem with multiple user classes. Transportation Research Part B, 40, 633-650.

HO, H. W., WONG, S. C. and SUMALEE, A. A congestion-pricing problem with a polycentric region and multi-class users: a continuum modeling approach. Transportmetrica, in press. 
IEA. 2006. $\mathrm{CO}_{2}$ emissions from fuel combustion 1971-2004. Paris: International Energy Agency.

JOUMARD, R., JOST, P., HICKMAN, J. \& HASSEL, D. 1995. Hot passenger car emissions modelling as a function of instantaneous speed and acceleration. Science of the Total Environment, 169, 167-174.

LI, Z. C., LAM, W. H. K., WONG, S. C. \& SUMALEE, A. Environmentally sustainable toll design for congested road networks with uncertain demand, International Journal of Sustainable Transportation, in press.

MCNALLY, M. G. \& KULKARNI, A. 1997. Assessment of influence of land usetransportation system on travel behavior. Transportation Research Record, 1607, 105115.

MESSENGER, T. \& EWING, R. 1996. Transit-oriented development in the Sun Belt. Transportation Research Record, 1552, 9.

NAGURNEY, A. 2000a. Congested urban transportation networks and emission paradoxes. Transportation Research Part D, 5, 145-151.

NAGURNEY, A. 2000b. Alternative pollution permit systems for transportation networks based on origin/destination pairs and paths. Transportation Research Part D, 5, 37-58.

NAGURNEY, A., QIANG, Q. \& NAGURNEY, L. S. 2010. Environmental impact assessment of transportation networks with degradable links in an era of climate change. International Journal of Sustainable Transportation, 4, 154-171.

NAGURNEY, A. \& RAMANUJAM, P. 1998. A multimodal traffic network equilibrium model with emission pollution permits: Compliance vs. noncompliance. Transportation Research Part D, 3, 349-374.

NORMAN, J., MACLEAN, H. L. \& KENNEDY, C. A. 2006. Comparing high and low residential density: Life-cycle analysis of energy use and greenhouse gas emissions. ASCE Journal of Urban Planning and Development, 132, 10-21.

NOWLAN, D. M. \& STEWART, G. 1991. Downtown population growth and commuting trips: Recent experience in Toronto. Journal of the American Planning Association, 57, 165-182.

POUDENX, P. 2008. The effect of transportation policies on energy consumption and greenhouse gas emission from urban passenger transportation. Transportation Research Part A, 42, 901-909.

RAKHA, H., AHN, K. \& TRANI, A. 2004. Development of VT-micro model for estimating hot stabilized light duty vehicle and truck emissions. Transportation Research Part D, 9, 49-74.

RAKHA, H., VAN AERDE, M., AHN, K. \& TRANI, A. A. 2000. Requirements for evaluating traffic signal control impacts on energy and emissions based on instantaneous speed and acceleration measurements. Transportation Research Record, 1738, 56-67.

SASAKI, T., IIDA, Y. \& YANG, H. User equilibrium traffc assignment by continuum approximation of network flow. The 11th International Symposium on Transportation and Traffic Theory (ISTTT11), 1990, Yokohama, Japan, 233-252.

SCORA, G. \& BARTH, M. 2006. Comprehensive Modal Emissions Model (CMEM), Version 3.01: User's Guide. University of California, Riverside Center for Environmental Research and Technology.

WONG, S. C. 1998. Multi-commodity traffic assignment by continuum approximation of network flow with variable demand. Transportation Research Part B, 32, 567-581.

WONG, S. C. \& YANG, H. 1999. Determining market areas captured by competitive facilities: A continuous equilibrium modeling approach. Journal of Regional Science, 39, 51-72. 
WONG, S. C., DU, Y. C., SUN, L. J. \& LOO, B. P. Y. 2006. Sensitivity analysis for a continuum traffic equilibrium problem. Annals of Regional Science, 40, 493-514.

WONG, S. C., LEE, C. K. \& TONG, C. O. 1998. Finite element solution for the continuum traffic equilibrium problems. International Journal for Numerical Methods in Engineering, 43, 1253-1273.

YANG, C., MCCOLLUM, D., MCCARTHY, R. \& LEIGHTY, W. 2009. Meeting an 80\% reduction in greenhouse gas emissions from transportation by 2050: A case study in California. Transportation Research Part D, 14, 147-156.

YANG, H. \& WONG, S. C. 2000. A continuous equilibrium model for estimating market areas of competitive facilities with elastic demand and market externality. Transportation Science, 34, 216-227.

YIN, Y. \& LAWPHONGPANICH, S. 2006. Internalizing emission externality on road networks. Transportation Research Part D, 11, 292-301.

ZIENKIEWICZ, O. C. \& TAYLOR, R. L. 1989. The Finite Element Method. New York: McGraw-Hill International Editions. 
Table 1: Parameters for the $\mathrm{CO}_{2}$ emissions estimation model

\begin{tabular}{cccc}
\hline$k$ & 1 & 2 & 3 \\
\hline$(i, j)$ & $-6.79 \mathrm{E}-01$ & $8.87 \mathrm{E}-01$ & $-7.28 \mathrm{E}-01$ \\
$(0,0)$ & $5.34 \mathrm{E}+02$ & $5.88 \mathrm{E}+02$ & $0.00 \mathrm{E}+00$ \\
$(0,1)$ & $2.49 \mathrm{E}+05$ & $4.77 \mathrm{E}+05$ & $3.65 \mathrm{E}+05$ \\
$(0,2)$ & $-7.34 \mathrm{E}+07$ & $-8.32 \mathrm{E}+07$ & $-5.73 \mathrm{E}+06$ \\
$(0,3)$ & $3.26 \mathrm{E}-02$ & $7.79 \mathrm{E}-02$ & $2.74 \mathrm{E}-02$ \\
$(1,0)$ & $-3.37 \mathrm{E}-04$ & $-9.51 \mathrm{E}-04$ & $-2.53 \mathrm{E}-04$ \\
$(2,0)$ & $1.97 \mathrm{E}-06$ & $6.10 \mathrm{E}-06$ & $2.58 \mathrm{E}-06$ \\
$(3,0)$ & $2.08 \mathrm{E}+01$ & $1.68 \mathrm{E}+01$ & $4.40 \mathrm{E}+01$ \\
$(1,1)$ & $-9.99 \mathrm{E}-02$ & $4.43 \mathrm{E}-01$ & $-4.76 \mathrm{E}-01$ \\
$(2,1)$ & $2.89 \mathrm{E}-04$ & $-3.71 \mathrm{E}-03$ & $3.23 \mathrm{E}-03$ \\
$(3,1)$ & $1.43 \mathrm{E}+03$ & $-1.59 \mathrm{E}+04$ & $-9.42 \mathrm{E}+03$ \\
$(1,2)$ & $1.76 \mathrm{E}+01$ & $9.24 \mathrm{E}+02$ & $7.06 \mathrm{E}+02$ \\
$(2,2)$ & $-5.15 \mathrm{E}-01$ & $-6.39 \mathrm{E}+00$ & $-4.33 \mathrm{E}+00$ \\
$(3,2)$ & $-3.18 \mathrm{E}-01$ & $0.00 \mathrm{E}+00$ & $-5.74 \mathrm{E}-01$ \\
$(3,1)$ & $6.27 \mathrm{E}+00$ & $-2.27 \mathrm{E}+01$ & $6.82 \mathrm{E}+01$ \\
$(3,2)$ & $-3.66 \mathrm{E}+02$ & $0.00 \mathrm{E}+00$ & $-1.38 \mathrm{E}+03$ \\
$(3,3)$ & & & \\
\hline
\end{tabular}


Table 2: The attractions to the two CBDs ( $Q_{m n}$ veh/h) and $\mathrm{CO}_{2}$ emissions ( $E$ million $\mathrm{g} / \mathrm{h}$ )

\begin{tabular}{cccccc}
\hline & $Q_{11}$ & $Q_{12}$ & $Q_{21}$ & $Q_{22}$ & $E$ \\
\hline Original situation & 22710 & 22290 & 23542 & 41458 & 493.89 \\
Uniform housing allocation & 22693 & 22307 & 23536 & 41464 & 494.00 \\
Optimal housing allocation & 22648 & 22352 & 23567 & 41433 & 484.74 \\
\hline
\end{tabular}




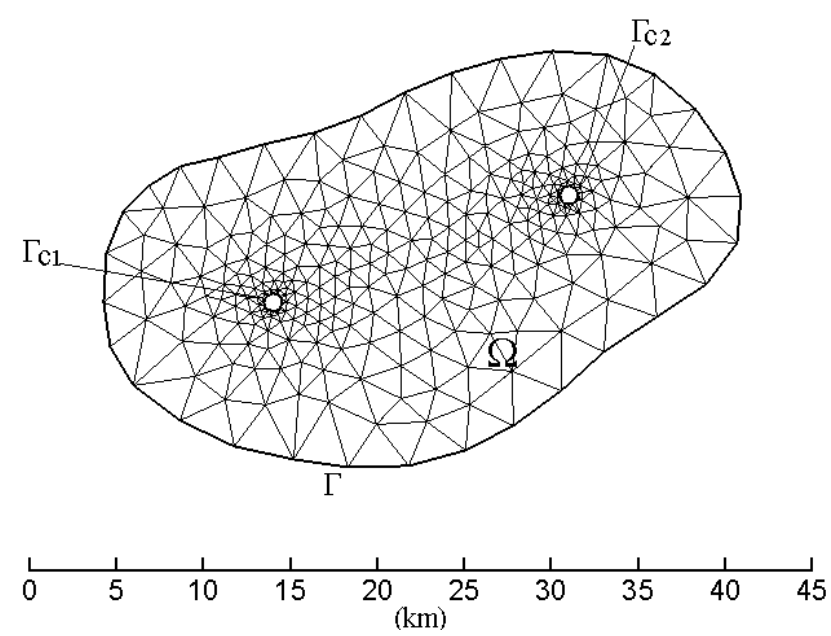

Figure 1: The modeled city and the finite element mesh generated. 


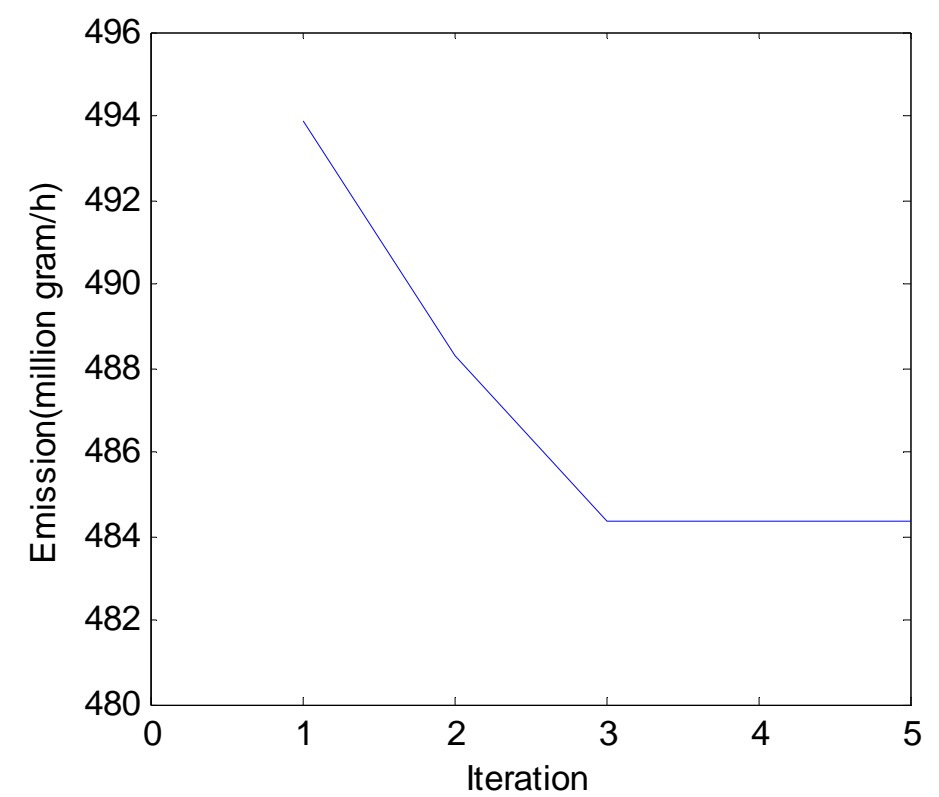

Figure 2: Typical convergence plot for the solution. 


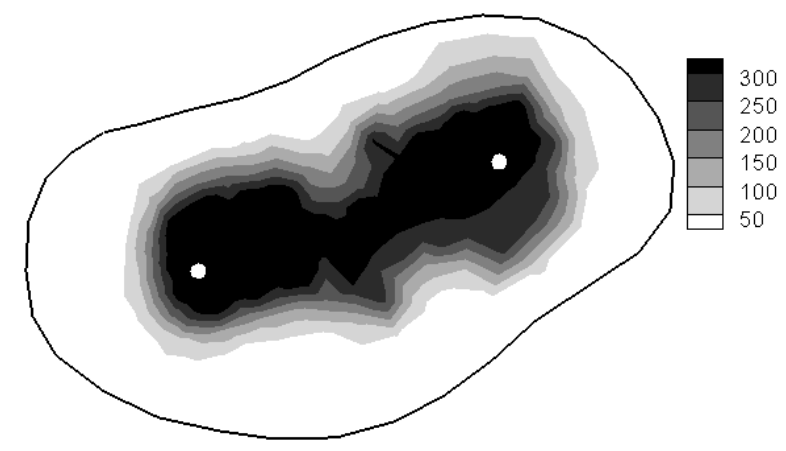

Figure 3: Optimal distribution of housing units (units $/ \mathrm{km}^{2}$ ). 
(a) Class 1 users traveling to CBD 1

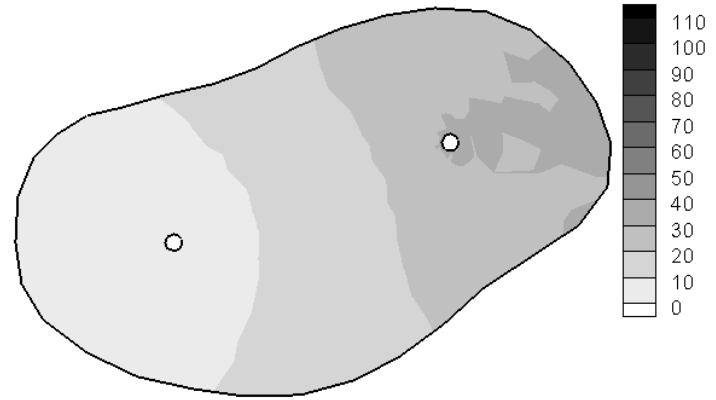

(c) Class 2 users traveling to CBD 1

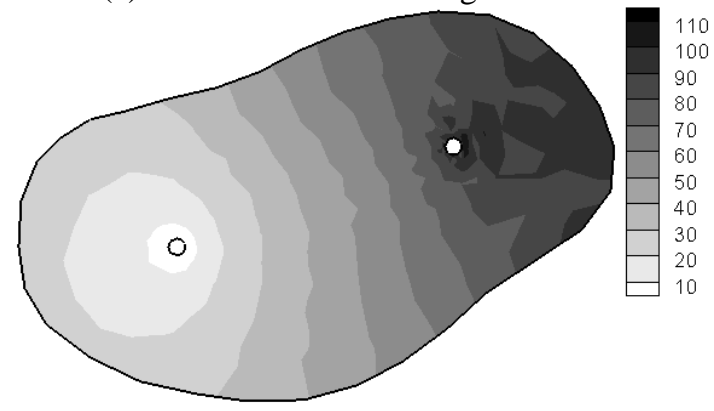

(b) Class 1 users traveling to CBD 2

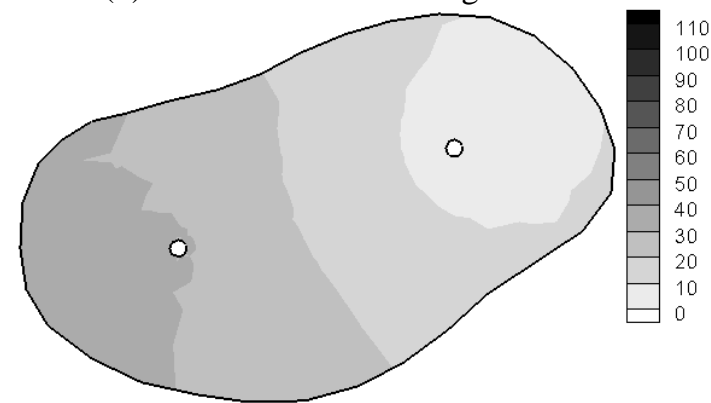

(d) Class 2 users traveling to CBD 2

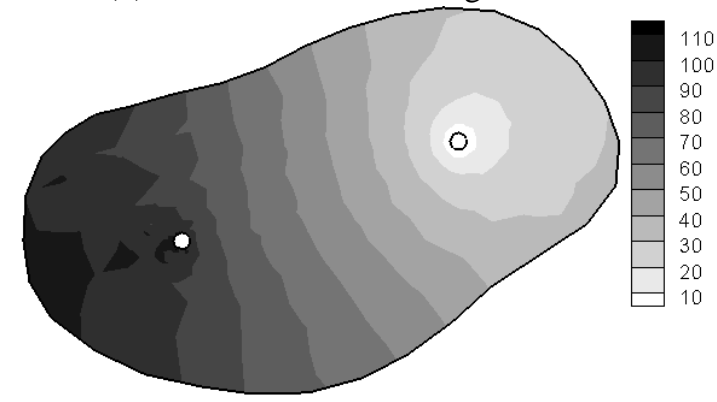

Figure 4: Transportation costs (HKD). 
Uniform housing allocation (a, c, e, g)

(a) Class 1 users traveling to CBD 1

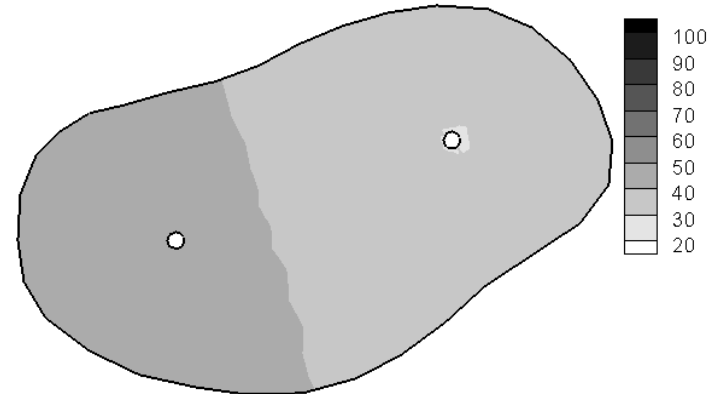

(c) Class 1 users traveling to CBD 2

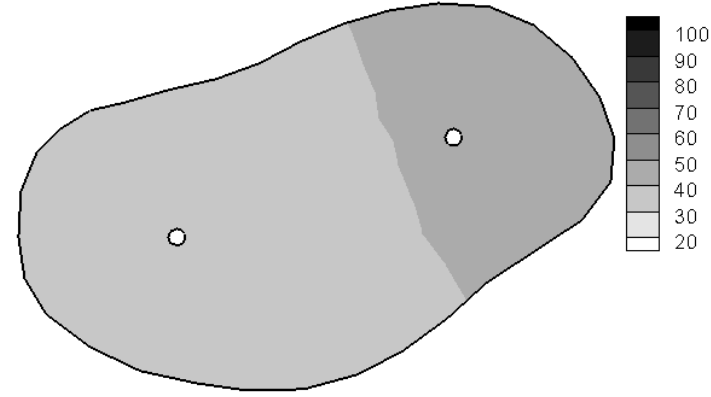

(e) Class 2 users traveling to CBD 1

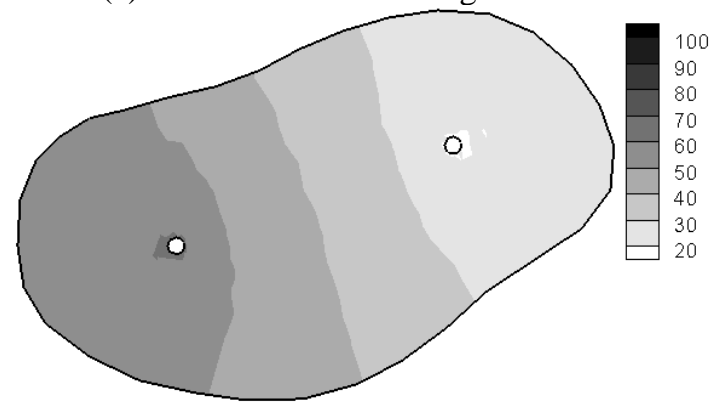

(g) Class 2 users traveling to CBD 2

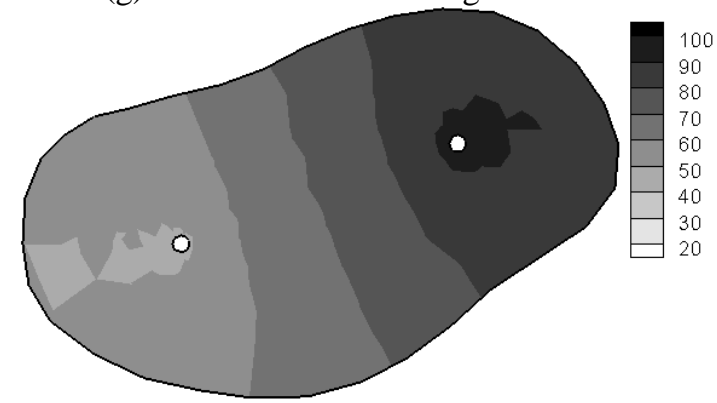

Optimal housing allocation (b, d, f, h)

(b) Class 1 users traveling to CBD 1

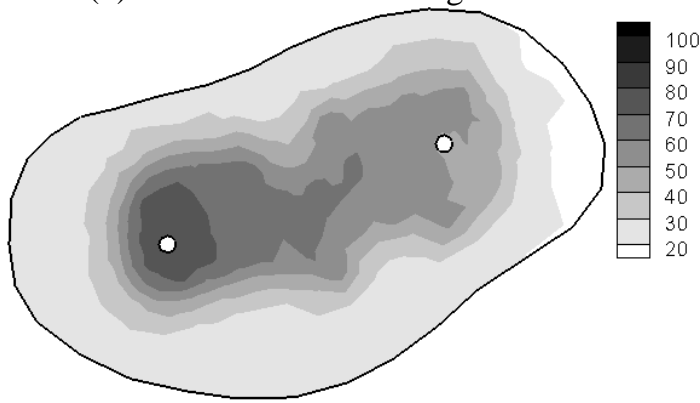

(d) Class 1 users traveling to CBD 2

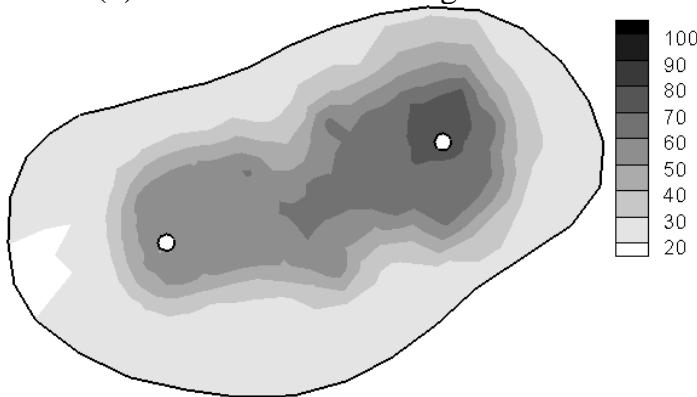

(f) Class 2 users traveling to CBD 1

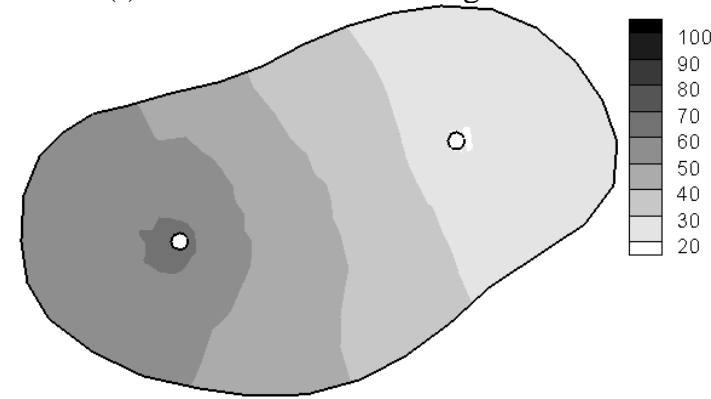

(h) Class 2 users traveling to CBD 2

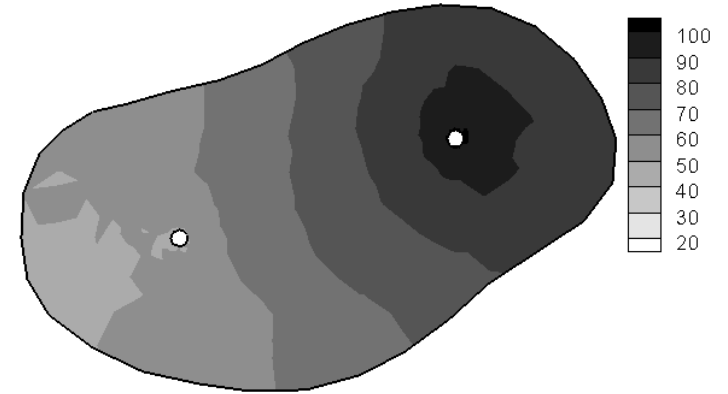

Figure 5: Demand contours (veh/h/ $/ \mathrm{km}^{2}$ ). 


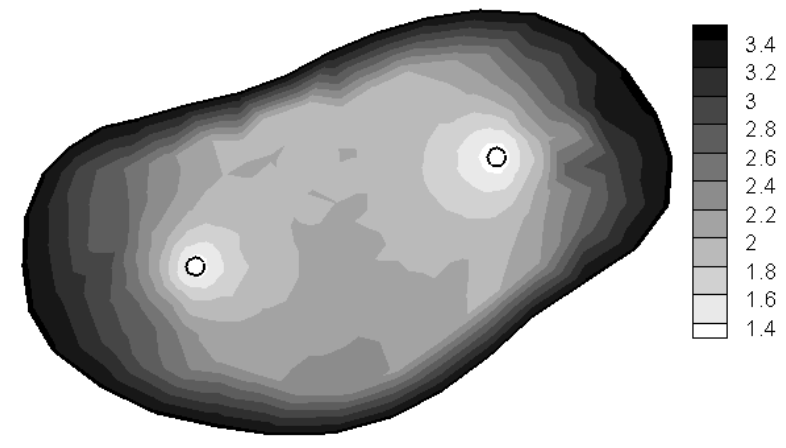

Figure 6: $\mathrm{CO}_{2}$ emission rate for class 1 commuters heading to CBD $1\left(10^{3} \mathrm{mg} / \mathrm{veh} / \mathrm{s}\right)$. 


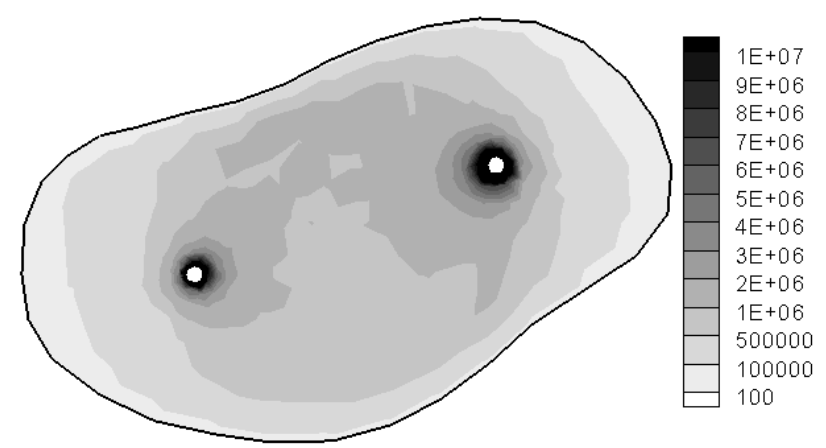

Figure 7: Distribution of total traffic-related emissions $\left(\mathrm{g} / \mathrm{h} / \mathrm{km}^{2}\right)$. 
(a) Sensitivity to budget B.

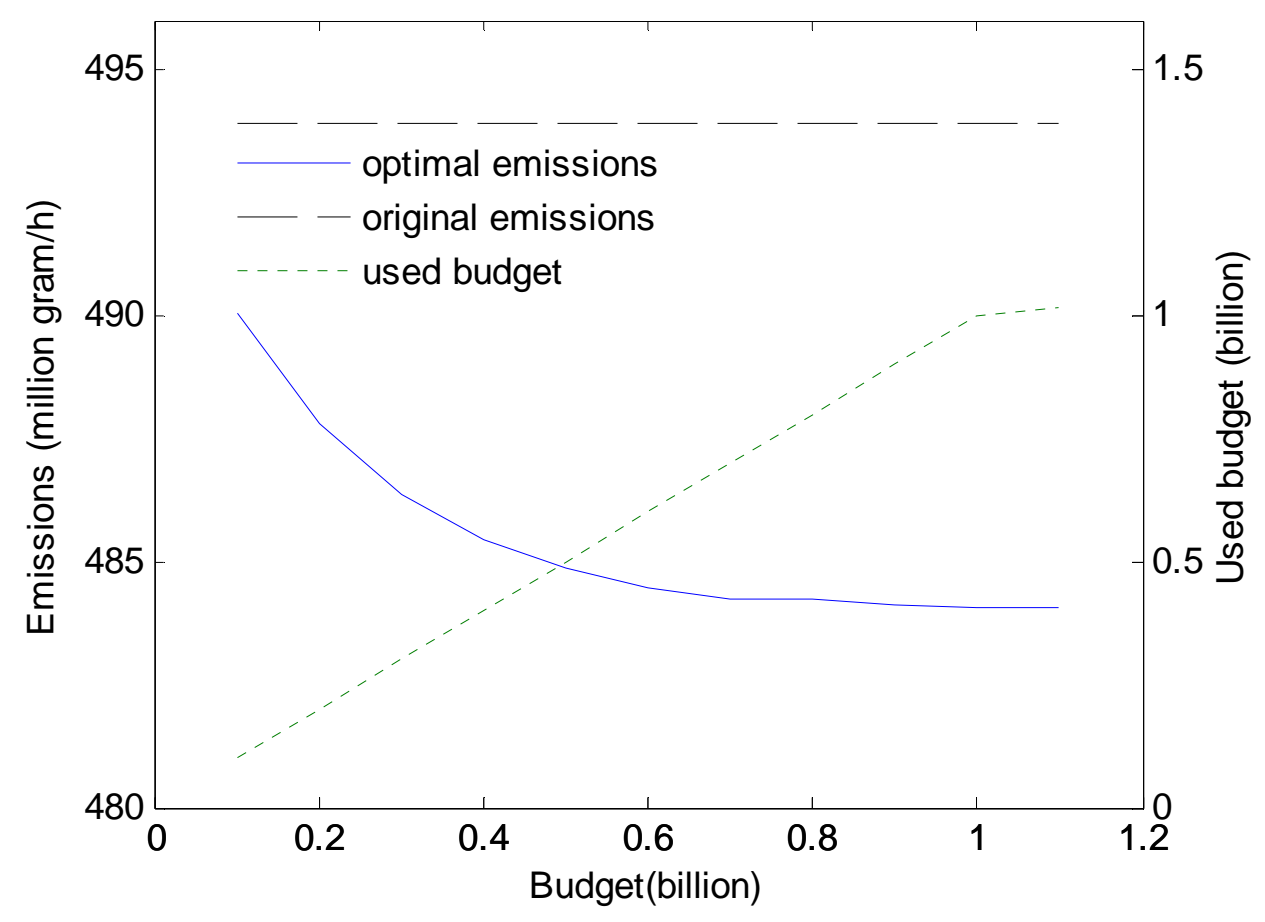

(b) Sensitivity to housing costs parameter $\beta$.

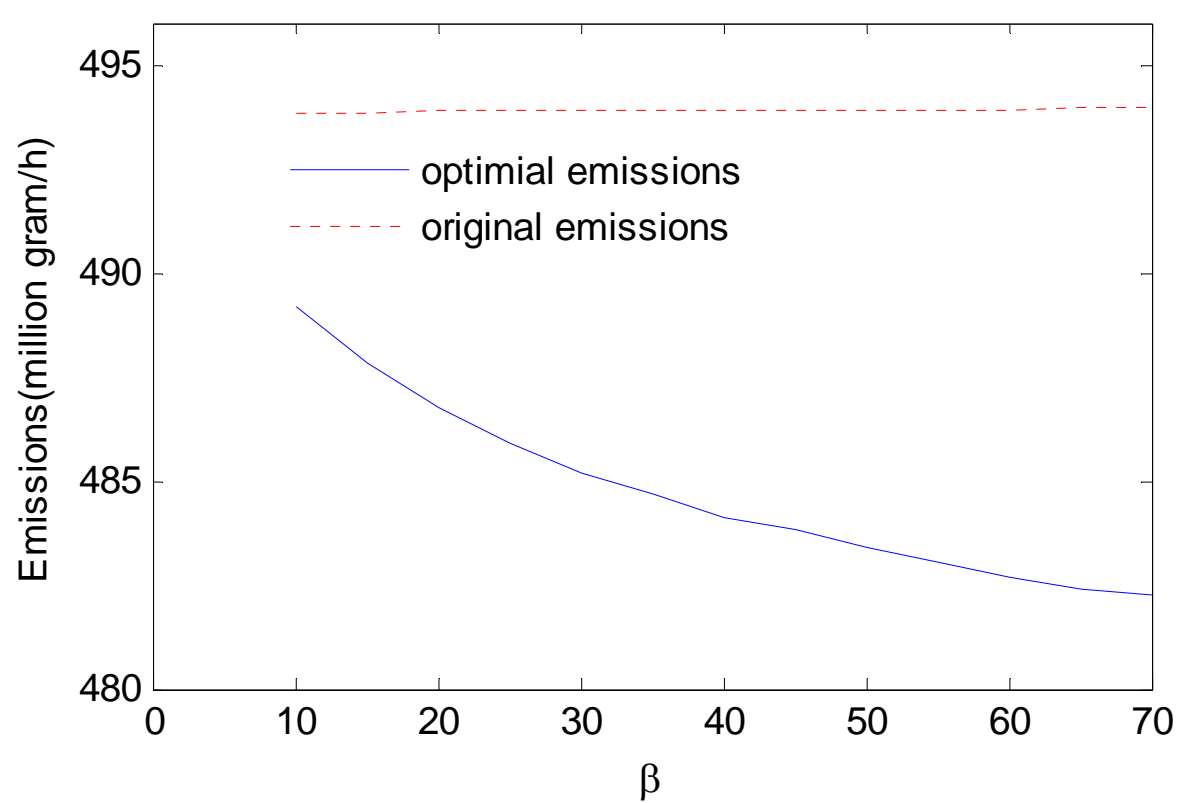

Figure 8: Sensitivity analysis. 